\title{
Barreras y tensiones de participación política de las víctimas en el contexto de los procesos de reparación colectiva: el caso de El Dorado \\ y El Castillo - Meta en el marco de la transición política en Colombia
}

Barriers and tensions in political participation for victims in the context of collective reparation processes in the case of El Dorado y El Castillo - Meta in the context of Colombia's political transition

Obstáculos e tensões de participação política das vítimas no contexto dos processos de reparação coletiva. O caso de El Dorado e El Castillo-Meta na transição política em Colômbia

Obstacles et tensions dans la participation politique des victimes dans le contexte des processus de paix et de réparation collective dans les cas de El Dorado et El Castillo - la région du Meta dans le contexte de la transition politique en Colombie 


\author{
Alba Lucía Cruz Castillo \\ Estudios Doctorales en Antropología social, \\ Doctoranda en Educación en Educación y Sociedad, \\ Magister en Estudios de Familia y Desarrollo, Trabajadora Social, \\ Docente investigadora; miembro del Grupo de Investigación en Trabajo Social, \\ Equidad y Justicia Social \\ Universidad de La Salle, Bogotá - Colombia \\ Correo electrónico: alcruz@unisalle.edu.co
}

\title{
Oscar Javier Díaz Giraldo
}

Estudiante de noveno semestre del Programa de Trabajo Social

Universidad de La Salle, Bogotá - Colombia

Correo electrónico: odiaz08@unisalle.edu.co

\section{Resumen}

El presente texto reflexiona sobre las barreras y las tensiones que se les presentan a las víctimas en procesos de participación política en el contexto de la reparación colectiva enmarcada en la Ley 1448 de víctimas y restitución de tierras del 2011, en relación con la visibilización de los daños y afectaciones, la participación sobre las decisiones políticas de la planeación y ejecución de los diagnósticos, la realización de los planes de reparación y el seguimiento a estos, que hacen que, finalmente, sus voces no sean escuchadas y que se vea afectada la memoria histórica de los hechos, el ocultamiento de actores y que la dimensión colectiva de la reparación se diluya en medio de la revictimización, la falta de sostenibilidad de los procesos y la corrupción, que llegan a jugar un papel fundamental en una implementación de la ley lenta y con poca eficacia. En

\section{Cómo citar este artículo:}

Cruz, A. L. \& Díaz, O. J. (2019). Barreras y tensiones de participación política de las víctimas en el contexto de los procesos de reparación colectiva: el caso de El Dorado y El Castillo - Meta en el marco de la transición política en Colombia. Revista de la Facultad de Derecho y Ciencias Políticas, 49 (131), pp. 422-449. doi: http://dx.doi.org/10.18566/rfdcp.v49n131.a08

Recibido: 19 de febrero de 2019.

Aprobado: 25 de julio de 2019. 
primera instancia, el artículo contextualiza la conflictividad en los municipios de El Castillo y El Dorado - Meta, y posteriormente ubica el rol de la memoria en los procesos de visibilización de daños. En un tercer apartado se ilustra algunas barreras que han sido expuestas por organismos y colectivos de víctimas en los procesos de participación política de las mismas, y finalmente se expone el caso participar de los municipios mencionados, en los cuales se recogió el testimonio de 20 víctimas pertenecientes a los comités de impulso y cuatro actores institucionales en los municipios, a través de entrevistas a profundidad desde el enfoque narrativo realizadas en el 2018; adicionalmente, el proceso investigativo contó con acompañamiento a organizaciones víctimas durante este período, el cual fue registrado y sistematizado en diarios de campo.

\section{Palabras clave}

Memoria colectiva, participación política, reparación colectiva.

\section{Abstract}

The present paper aims to reflect about barriers and tensions that are presented to victims in political participation processes in the context of collective reparation framed in Ley 1448 which regards victims and land restitution in 2011. All of it in relation to the visibility of damage and detriment, the participation in political decisions about planning and executing diagnostics, the elaboration of plans to repair and follow-up these, which finally causes their voices to not be heard and historical memory of the facts to get damaged, the concealment of participants and the collective dimension of reparation to be diluted in the middle of revictimization, the lack of sustainability of the processes and corruption, which play a fundamental role in the implementation of a slow and scarcely effective law. Firstly, the paper contextualizes the conflict in the municipalities of El Castillo and El Dorado - Meta, afterward locates the role of the memory in the processes of visibility of damage, in a third section it illustrates some barriers that have been exposed by organizations and collectives of victims in the processes of political participation of the victims, and finally the case of the mentioned municipalities is presented; In which the testimonies of 20 victims belonging to the Comités de Impulso and 4 institutional participants of the municipalities were gathered, via narrative approach in-depth interviews in the year 2018. Additionally, the investigation process counted with a process of victim organizations follow-up during this period which was recorded and systematized in field journals.

\section{Key Words}

Collective Memory; political participation; collective reparation 


\section{Resumo}

O presente texto estuda os obstáculos e as tensões que se apresentam às vítimas nos processos de participação política, no contexto de reparação coletiva da Lei 1448 de vítimas e restituição de terras de 2011 no que diz respeito à visibilização dos danos e afetações, à participação nas decisões políticas de planejamento e implementação dos diagnósticos, à realização dos projetos de reparação e ao acompanhamento deles. Os quais, finalmente, ocasionam que suas vozes não sejam ouvidas e que a memória histórica dos fatos seja prejudicada, assim como a ocultação dos atores e a dissolução da dimensão coletiva da reparação na re-vitimização, a falta de sustentabilidade dos processos e a corrupção têm um papel fundamental a desempenhar na implementação da lei lenta e pouco eficaz. Em primeiro lugar, o artigo contextualiza o conflito nos municípios de El Dorado e El Castillo-Meta. Depois, estabelece-se a função da memória nos processos de visibilização dos danos. Em terceiro lugar, ilustram-se os obstáculos que têm sido expostos pelos organismos e coletivos de vítimas nos processos de participação política das vítimas. Finalmente, expõe-se o caso dos municípios estudados, onde se recolheu o testemunho de 20 vítimas pertencentes aos Comitês de Impulso e 4 atores institucionais nos municípios através das entrevistas em profundidade, desde a perspectiva narrativa em 2018. Além disso, a pesquisa desenvolveu um processo de acompanhamento às organizações de vítimas durante esse período, o que foi registrado e sistematizado em diários de campo.

\section{Palavras chaves}

Memória coletiva, participação política, reparação coletiva.

\section{Résumé}

Le présent article est une réflexion sur les obstacles et les tensions qui se présentent aux victimes dans le processus de participation politique dans le contexte de réparation collective encadrée par la Loi 1448 sur les victimes et restitutions de terres de 2011, traitant de la visibilisation des dommages et affectations, de la participation aux décisions politiques de planification et d'exécution des diagnostics, de la réalisation des plans de réparation et du suivi de ceux-ci. Ces tensions et obstacles font que finalement leurs voix ne soient pas écoutées et que la mémoire historique des faits se voit affectée, que les acteurs soient occultés, que la dimension collective de la réparation soit diluée au milieu de la re victimisation, que les processus manquent de durabilité et que la corruption joue un rôle fondamental dans l'implantation d'une loi lente et peu efficace. Dans un premier temps, l'article contextualise le conflit dans les municipalités d'El Castillo et d'El Dorado - Meta, puis il cerne le rôle de la mémoire dans les processus de visibilité des dommages, et dans une troisième partie, il illustre certains obstacles soulignés par des organisations et des groupes de victimes dans les processus de participation politique des victimes. Enfin le cas des municipalités mentionnées est présenté, municipalités dans lesquelles ont été recueillis les témoignages de 20 victimes appartenant aux comités d'Impulso et de 4 
acteurs institutionnels des municipalités, grâce à des entretiens approfondis conduits avec une approche narrative en 2018. En outre, le processus d'enquête a mis un place une procédure d'accompagnement des organisations de victimes au cours de cette période, qui a été enregistrée et systématisée dans des journaux de terrain.

\section{Mots clés}

Mémoire collective, participation politique, réparation collective

\section{Introducción}

El conflicto sociopolítico y armado colombiano que ha tenido lugar por más de cincuenta años en el país, y que es denominado como el de mayor duración en Suramérica, ha dejado diversas marcas que se reflejan en las condiciones de vida de los habitantes del país, quienes a partir de los hechos victimizantes que dejó el paso de la guerra por sus vidas, se vieron afectadas en los ámbitos individual y colectivo en aspectos psicológicos, culturales, sociales, ambientales, económicos y políticos.

Uno de los departamentos que históricamente se ha caracterizado por ser un territorio con fuerte presencia de los grupos armados y por una constante conflictividad, por causas económicas, políticas, ideológicas, sociales, por las condiciones ambientales del territorio, y por presencia militar, dada su ubicación geográfica como corredor estratégico para los grupos armados y por la extracción minera y de hidrocarburos, ha sido el departamento del Meta.

Como respuesta del Estado a las dinámicas del conflicto social y armado en Colombia, surge la Ley 1448 de 2011, como el medio por el cual el Gobierno expresó su interés por las víctimas del conflicto armado, con la intención de resarcir los daños ocasionados a la población civil, ya sean de índole económica o moral. A partir de la misma, se crea la Unidad de Atención y Reparación Integral a Víctimas, que es la entidad encargada de dar cumplimiento y seguimiento a los lineamientos de la Ley 1448 de 2011; con lo anterior aparece también, la figura de sujeto de reparación colectiva, que para efectos de la presente Ley, según el Artículo 152, "serán 1. Grupos y organizaciones sociales y políticos; 2. Comunidades determinadas a partir de un reconocimiento jurídico, político o social que se haga del colectivo, o en razón de la cultura, la zona o el territorio en el que habitan, o un propósito común” (Agencia Presidencial para la Acción Social y la Cooperación Internacional, 2011, p.6); dentro de esta misma ley se 
enuncia que la participación de estos sujetos es fundamental para establecer la ruta de Reparación Colectiva y que, por lo tanto, es de la mano de ellos que esto se realiza.

El acercamiento a este tema reviste gran relevancia para la sociedad, dado el momento histórico de transición política que vive el país en relación con el conflicto armado interno y los impactos que esto tiene sobre la población sujeto de reparación colectiva, quienes, a partir de iniciativas de carácter simbólico, cultural y político se han esforzado por recuperar la memoria, para fortalecer el ejercicio de diagnosticar los daños y sus afectaciones en lo territorial como mecanismo de visibilización de los impactos de la guerra en la vida colectiva de sus pobladores y en la dinámica sociocultural de los pueblos. Dentro de los espacios de participación de las víctimas en los procesos de reparación colectiva se crea el Comité de Impulso como:

Un grupo de personas, representativo del sujeto de reparación colectiva, responsable de estimular el proceso y de interlocutar con la Unidad para las Víctimas. Se debe garantizar que los distintos liderazgos y los sujetos de especial protección encuentren representación en este espacio. Para el caso de comunidades étnicas, se denomina grupo de apoyo o podrá tomar el nombre que la comunidad prefiera y contará con la participación de las autoridades tradicionales, representativas y otros líderes y lideresas de la comunidad. (Unidad para la Atención y Repración Integral a Víctimas, 2014, p. 2)

En este sentido, el Comité de Impulso está pensado para plantear un diálogo que permita que las voces de las víctimas sean visibilizadas políticamente y en ello sus narraciones, sus relatos y, sobre todo, para que se reconstruya con ellos la memoria de lo sucedido en torno de la búsqueda de la verdad, la reparación y la no repetición.

El siguiente apartado ilustra la conflictividad, particularmente en los municipios de El Castillo y EL Dorado, departamento del Meta, con la intención de plantear y problematizar, desde allí, la violencia sistemática en estos territorios y las razones por las cuales estos municipios llegan a ser acogidos dentro de la Ley 1448 como sujetos de reparación colectiva, y de igual manera, se hace énfasis en la manera particular en que el conflicto ha marcado las relaciones con el Estado y las formas concretas en que la población ha constituido su vivencia con dicha conflictividad. 


\section{Contextualización de la conflictividad en El Dorado y El Castillo}

Los dos municipios aquí referenciados han sido territorios de disputa y de confrontación histórica de la guerra en Colombia, han sido escenarios en donde el conflicto, el miedo y, en ocasiones la resistencia, se han instalado como parte de la historia que los ha constituido y ha marcado diferencias en relación con la particularidad del conflicto.

\subsection{El Dorado, historia de huida}

El conflicto en el municipio de El Dorado (Meta), data de la guerra bipartidista en Colombia, que se empieza a desarrollar a mediados de los años 40, con la conformación guerrillera del Indio Quintín Lame, quien buscaba el reconocimiento de la identidad y la tierra de los pueblos indígenas. Por el lado de las posturas de derecha se dio la conformación de los Chulavitas para la restauración del conservadurismo en las urbes y la ruralidad, lo que implicaba desencadenar la guerra bipartidista entre liberales y conservadores. Es oportuno mencionar que la Iglesia católica jugó un papel importante para el mantenimiento del status quo (Comisión Histórica del Conflicto Armado, 2015. Pág. 606)

De manera que la violencia política es un factor fundamental para la disputa de territorios de la zona, por cuestiones ideológicas, económicas y sociales. La guerra dio como particularidad que muchas de las personas que llegaron al territorio de El Dorado huían de la guerra bipartidista de la ideología conservadora; ellos delimitaron el territorio de El Dorado, que pertenecía con anterioridad al municipio de Cubarral (Molano, 1989. Pág. 289). En la mayoría de estos pueblos empezaron a surgir móviles de autodefensa campesina, que posteriormente, en el transcurso de las conferencias de autodefensas guerrilleras, se autodenominarían Farc (Fuerzas Armadas Revolucionarias de Colombia). Que no solo eran un grupo de autodefensa contra ataques del conservadurismo, en realidad ejercían jurisdicción sobre estos territorios, no solo en aspectos políticos sino también en lo que competía a la convivencia, reglamentarios; adicionalmente, con un carácter de empoderamiento de las comunidades para poder establecer mecanismos de exigibilidad hacia el estado para la obtención de recursos. (Proyecto Colombia Nunca Más, 2000). 
En los años 80, esta guerra sigue en medio de la disputa por la tierra, y es allí donde adicionalmente, en los territorios con antecedentes conservadores como El Dorado, emergen los grupos paramilitares, que se nutren de la explotación ilegal de piedras, además de los cultivos de marihuana y coca. Para muchos autores los dos actores armados ilegales son narco paramilitares y narcoguerrilleros, caracterizados por su peligrosidad y por sus diversas acciones violentas (Proyecto Colombia Nunca Más, 2000) que llegaron a permear los territorios de El Dorado.

Mediante la Resolución N. . 2013 - 3063319 del 25 de noviembre de 2013, el municipio de El Dorado es declarado sujeto de reparación colectiva, y en este lugar se identifican los siguientes problemas: daño a bienes colectivos y minado de territorio, vulneración del derecho a la seguridad y confinamiento y restricción a la libre circulación. En este sentido es pertinente hacer un contraste con las acciones que se han pensado para el cumplimiento de la ruta de reparación integral, puesto que lo planteado en esta resolución no comprende la realidad de las afectaciones o impactos que ha generado el conflicto armado en el municipio de El Dorado.

\subsection{El Castillo, historia de resistencia}

Al hablar del municipio El Castillo, es imprescindible referirse al conflicto y sus precursores; tras la ola fuerte de la violencia bipartidista, se da la llamada “colonización” del Ariari, siendo entonces una zona colonizada y conformada por personas que venían desplazadas de distintas regiones del país, como Boyacá, Tolima, Huila y Cundinamarca. En municipios como El Dorado se asentaron familias de corte conservador, en su mayoría, marcando así un impulso colonizador; de otro lado, en El Castillo se asentaron familias mayoritariamente de corte liberal (Centro Nacional de Memoria Histórica, 2015, p.56).

Con la llegada de estas familias al territorio se empezó a construir un pensamiento político mancomunado que traza la historia de lucha y resistencia del municipio de El Castillo, siendo el Partido Comunista Colombiano (PCC), uno de los primeros alentadores de las luchas sociales en el Ariari. Este contexto permitió, entonces, la formación política de jóvenes y adultos dentro de una corriente de izquierda, lo que marcó un hito en la historia del municipio e indicó el inicio y aliento de la lucha social y la resistencia frente a las dinámicas del entorno.. 
Durante la colonización del Ariari, en El Castillo, tras la instalación del PCC en el municipio y la ola de creación de las guerrillas liberales con la lucha política y económica que se vivía en el país y el asesinato de Gaitán, llegaron dirigentes liberales y comunistas al municipio, quienes se adhirieron a esta estructura política persistente allí y "se dedicaron a una intensa labor de instrucción política entre los colonos, con lo cual lograron que los hombres se enrolaran en el PCC, los jóvenes en las Juventudes Comunistas, los niños en la Unión de Pioneros José Antonio Galán y las mujeres en la Unión de Mujeres Demócratas” (Centro Nacional de Memoria Histórica, 2015. p. 53).

Entendiendo esto, históricamente El Castillo ha sido considerado epicentro de izquierda y, en este sentido, ha sido uno de los territorios masacrados por el conflicto armado interno, no solamente por una guerra política e ideológica, sino que, de igual forma, por el azote del brazo económico del conflicto, en cuanto a que este territorio, por su ubicación, es un punto estratégico, siendo un corredor para las lógicas paramilitares, narcoproductivas y para el acceso a distintos puntos del país, lo que lo convierte en un punto de referencia como un territorio que quería ser dominado y controlado por los distintos actores armados que en él ejercieron violencia (Observatorio del programa presidencial de derechos humanos y DIH, 2007. p.3)

La particularidad del municipio El Castillo radica en las distintas formas y ejercicios de violencia que se llevaron a cabo en el territorio, siendo entre los años 2000 y 2006 aproximadamente el lapso de tiempo con mayor violencia en el municipio, entendiendo que el ingreso del flagelo paramilitar en el territorio tomó fuerza desde 1997, Lo que incrementó las lógicas violentas del conflicto (PNUD, 2010, Pág. 9); de esta forma, por ejemplo, en el 2003 se presentó un índice de homicidios de 727 por cada cien mil habitantes (Observatorio del programa presidencial de derechos humanos y DIH, 2007) siendo esto prueba fehaciente de la magnitud y la fuerza del conflicto armado en este pueblo perdido en el piedemonte llanero.

Las dinámicas del conflicto en este municipio fueron múltiples: en la cabecera municipal se presentó una lógica de enfrentamiento continuo entre la guerrilla de las Farc y la fuerza pública, en la zona rural, la cual se encuentra distribuida en siete núcleos zonales (Cabecera Municipal, Miravalles, Puerto Esperanza, Alto Cal, La Cumbre, El Cable, Medellín del Ariari). Se debe anotar que se vivió una realidad particular en cada uno de estos espacios; por ejemplo, en el núcleo zonal de Medellín del Ariari, en ambos costados de la carretera principal que va hacia El Castillo se encuentran las veredas Playa Rica (parte 
de “abajo”) y la vereda Malavar (parte de “arriba”). La lógica entre estas veredas y, en general, de todas las veredas separadas por esta vía central, se basó en la confrontación entre la guerrilla de las Farc y las AUC, por lo cual las relaciones sociales se vieron afectadas en el sentido de que los que habitaban la parte baja no subían por miedo a que allí estuvieran los paramilitares, y los que habitaban “arriba” no bajaban por la presencia de la guerrilla de las Farc, situación que rompe totalmente el tejido social entre las veredas del municipio y provoca que espacios como las casas, trochas y fincas se conviertan en campos de batalla.

Por medio de una resolución, la unidad para las víctimas reconoció, en el 2014, al municipio de El Castillo como sujeto de reparación colectiva; sin embargo, este reconocimiento solo se dio en la cabecera municipal, desconociendo y dejando de lado el flagelo del conflicto y las dinámicas atroces de este en la comunidad rural, que representa la mayor parte del territorio, tras la exigencia del reconocimiento y la lucha social que se respira en el municipio, siendo esta una de las características del territorio. En el 2016, la unidad de víctimas extendió el reconocimiento de sujeto de reparación a la totalidad del municipio.

En el contexto de la conflictividad de los municipios de El Castillo y El Dorado - Meta, la investigación de carácter cualitativo indagó por los obstáculos que se le presentan a los participantes de los comités de impulso de los dos municipios en relación con la participación política como representantes de las víctimas de sus territorios; en esta indagación la investigación da relevancia al papel que la memoria tiene en los procesos de reconstrucción y reconocimiento de los daños, no solo como medida de satisfacción dentro del marco de la ley, sino como de motor frente a los procesos colectivos necesarios para visibilizar la voz de las víctimas. En este sentido, la investigación presenta una reflexión sobre dicha categoría como punto de partida para indagar por las barreras políticas que, desde las narrativas de las víctimas con un acompañamiento psicosocial provisto a las mismas durante un año, se pudieron deducir a través del análisis narrativo, compartiendo con ellos diferentes espacios formales e informales.

\section{Memoria colectiva: espacio para visibilizar los daños comunes}

Al hacer referencia al surgimiento del concepto de memoria colectiva es preciso mencionar que la memoria cobra relevancia, como lo señala Jean Duvignaud en el prólogo del libro Memoria colectiva, de Maurice Halbwachs 
(Halbwachs, 1950) en el momento en que la continuidad de las sociedades europeas se ven interrumpidas, haciendo alusión a la guerra de 1914, en donde el pasado o la historia buscan imponerse como principios para determinar la imagen de la realidad de las personas, el espacio y del mundo, poniendo en riesgo la conciencia universal, ya que la imposición de la historia como doctrina también determinaría la conciencia; esta es una de las preocupaciones para acercarse a la memoria colectiva.

La memoria para, Maurice Halbwachs (1950), está integrada por dos elementos: el primero es la memoria histórica, la cual está dada por elementos como datos, textos del presente que contribuyen a reconstruir el pasado, y el segundo es la memoria colectiva trazada por la conciencia individual y general, la cual, para el autor, está determinada por nuestro recuerdo personal, pero también por medio de testimonios y testigos, los cuales, por medio de la reconstrucción de momentos vividos, devela que la memoria está edificada desde los recuerdos compartidos que refuerzan, dan origen y precisión a lo vivido, y a los múltiples testimonios de recuerdos específicos, que determinan una realidad colectiva acerca del pasado al que se hace memoria, aun si se encuentran divergencias o distanciamientos en los testimonios expresados de forma individual, puesto que nuestros recuerdos están trazados por la subjetividad, y es por ello que los testimonios de los demás pueden complementar o dar precisión a los recuerdos.

En este sentido, el papel de las víctimas en procesos de reparación y reconstrucción es fundamental, porque es a través de sus narraciones donde se hacen visibles los daños, las afectaciones y las transformaciones que estos han causado en su vida cotidiana (Zamora \& Reyes Mate,2011. p.5). Estos autores acuñan el término de justicia anamnética para referirse a aquella justicia que va más allá de la normatividad y se pregunta por los derechos negados del pasado, por la manera en que estos han perpetuado el daño a las víctimas,

por los vínculos entre la injusticia presente y la pasada. A partir de este vínculo se hace patente que hacer justicia no consiste solo en castigar al culpable, sino también en adoptar la perspectiva de las víctimas. Para construir un mundo basado en la justicia es imprescindible la memoria. (pp. 5-6).

Este ejercicio de reconocimiento de las injusticias que permanecen es trascendental para el tránsito de la disputa en la violencia a la disputa en la justicia (Vargas Valencia, 2013; Garay Salamanca, 2014). 
El reconocimiento de las injusticias es fundamental en el contexto de la visibilización de los daños colectivos, los cuales según Bello (2014) se relacionan con lo siguiente:

1. "Reconocer la valoración integral de la comunidad o la organización que ha sufrido el daño, considerando sus características sociales, culturales, su contexto político y económico.

2. Valorar los daños al grupo, determinando lo colectivo como parte del análisis; una determinación a priori, independientemente de la valoración integral de la persona.

3. No generalizar, no universalizar las afectaciones y los daños; estos deben explorarse en la magnitud de lo particular y lo territorial.

4. Explorar la integralidad y complejidad de los diagnósticos sociales de daño, en relación con este tema no solo debe diagnosticarse lo médico o lo psiquiátrico, pues en el caso de los daños morales, estos suponen unos sufrimientos subjetivos, que no necesariamente se expresa a través de síntomas o de cualquier otra alteración psicopatológica. (p.25)

Desde esta perspectiva en daño colectivo cuando la acción viola los derechos y bienes de las Comunidades, también se produce un daño colectivo cuando se vulneran masiva y sistemáticamente los derechos individuales de los miembros de la colectividad (Bello, 2014, p. 25). Comprender el lugar que ocupa la memoria colectiva en la socialización, exposición y puesta política del daño colectivo es fundamental para los procesos de reparación y construcción de tejido social; en tal sentido, la construcción de memoria colectiva no solo implica visibilizar los daños materiales y la restitución económica de estos; a esta pérdidas, que son significativas en lo colectivo, se suman los sentidos y los significados alrededor de las pérdidas que tienen un alto impacto en lo individual y en la cohesión de la comunidad; al ignorar las dimensiones sociales de la relación entre daño colectivo y memoria no se da tiempo y lugar a los duelos, a los planes futuros que garanticen la repetición, y se presencia un duelo aplazado que causa afectaciones culturales profundas.

La centralidad de la memoria en el proceso de lo colectivo se comprende más allá de recordar y de dignificar como una reivindicación ética, resulta como una plataforma de agencia política y apuesta hacia el futuro por parte de las víctimas. La memoria no debe entenderse entonces solo como una forma de nombrar el pasado sino también como una forma de problematizarlo; este, de acuerdo con Reátegui (2009, p. 25), es un factor que construye espacio 
público, es una sustancia social que puede ser utilizada para consolidar poder, pero también para desafiarlo, transformarlo o desestabilizarlo.

\section{La participación política de víctimas del conflicto armado en los procesos de reparación colectiva}

Desde una mirada estatal en la actual Ley de Víctimas y Restitución de Tierras (Ley 1448 de 2011), la participación de las víctimas se explica en el Artículo 261, como:

Artículo 261. Participación. Se entiende por participación aquel derecho de las víctimas a informarse, intervenir, presentar observaciones, recibir retroalimentación y coadyuvar de manera voluntaria, en el diseño de los instrumentos de implementación, seguimiento y evaluación de las disposiciones previstas en la Ley 1448 de 2011 y los planes, programas y proyectos implementados para fines de materializar su cumplimiento. (Ley 1448, 2011, art.261).

Si bien se establece en la legislación un papel de diálogo continuo con las víctimas en términos de reparación, los escenarios de participación aún se debaten entre la excesiva institucionalización y fenómenos como la estigmatización política de los participantes, en relación con esto, a las víctimas presentes en los procesos no se les ha generado la posibilidad de participar activamente en los ámbitos políticos, sociales y culturales que contemplan la reparación; es así que muchos escenarios de participación se han limitado a la exposición de los lineamientos institucionales sin tener en cuenta la opinión y las dinámicas comunitarias. Todo lo anterior implica una visión estática de las víctimas, ignorando su proceso histórico y su capacidad transformadora de los daños colectivos y del entorno.

Los autores Echavarría Rentería \& Hinestroza Cuesta (2016) afirman que a pesar de la existencia de algunos marcos legales en donde se consigna la inclusión de los grupos étnicos en los procesos de reparación, específicamente en la Ley 1448 de Víctimas y Restitución de Tierras, de 2011, y la Ley 975 de 2005 de Justicia y Paz, estas no presentan de forma concreta una conceptualización de lo que debe comprenderse por daño colectivo o de los elementos que permitan distinguirlo del daño individual; no incorporan 
variables étnicas, aunque establezca algunos lineamientos; no establecen ni diseñan una estructura administrativa y judicial idónea para la reparación colectiva con enfoque étnico; en otros términos, reconoce a los grupos étnicos como víctimas colectivas, pero no desarrolla medidas diferenciadas en razón de su etnicidad o cultura.

Estas falencias de la Ley pasan por otros asuntos relevantes que las comunidades étnicas reclaman, entre ellas, una verdadera apuesta de las comunidades negras en los procesos de reparación, ya que estas leyes no fueron consultadas con ellas mediante mecanismos como la consulta previa, y el trámite legislativo fue iniciado sin observar la garantía del derecho fundamental. Para El Centro Internacional de Justicia Transicional:

El problema de la reparación colectiva debería tener en cuenta que esta tendría que pensar primero en como satisfacer sus necesidades básicas insatisfechas Acceso a la vivienda, acceso a servicios sanitarios, acceso a educación y capacidad económica”. (Centro Internacional de Justicia Transicional, 2015, p. 78).

Para el CODHES (Consultoría para los Derechos Humanos y el Desplazamiento, 2012), el fundamento esencial de la reparación colectiva debe basarse en el reconocimiento de las comunidades y su relación con el territorio y la identidad cultural, los daños que se han causado a los procesos organizativos y sus capacidades en lo político y cultural.

En este sentido, la reparación debe enfocarse a re-conocer este tipo de daños mucho más estructurales, a desarrollar procesos que permitan la reconstrucción de los pueblos y sus organizaciones y, ante todo, a asegurar que se produzca un quiebre histórico en la sociedad colombiana. De este modo se dejarían atrás los fenómenos de victimización desproporcionada causados por el conflicto y, por demás, encadenados a la desprotección histórica de comunidades y pueblos, y a procesos de discriminación de larga duración. (p. 74).

Para las organizaciones sociales que han evaluado los procesos de reparación colectiva, "la falta de respuesta por parte de las instituciones responsables de cuestiones esenciales para que la reparación sea realmente integral” (Centro Internacional de Justicia Transicional, 2015, p. 23), de no ser así, no se puede hablar de una reparación real ni de un proceso de reivindicación de derechos para las víctimas del Conflicto sociopolítico y armado colombiano, y es que 
elementos primordiales en un proceso integral como la educación, la vivienda, la salud o la exención del servicio militar obligatorio, han sido percibidos como débiles por las víctimas de acuerdo con los esfuerzos de la Unidad para la Atención y Reparación a Víctimas.

Al hablar de la participación política, máxime en el ámbito del conflicto armado colombiano,, es indispensable acercarse a las barreras y tensiones que hay en cada una de las relaciones de poder establecidas en los procesos mismos de reparación tanto individual, como colectiva que se adelantan y se pretenden concretar, relaciones como lo pueden ser institución-victima, Estadovíctima, actores armados-víctimas, sociedad civil-víctima, donde entran en juego elementos legales, institucionales, organizacionales, sentimentales, físicos o de otra índole, que se juntan y mueven la balanza de los procesos de reparación por parte y parte (Estado - victimario - víctima - sociedad civil).

Es posible ubicar las barreras desde el inicio de los procesos de paz que se han llevado a cabo a través de la historia y los distintos deseos de reparar a las víctimas, desde la legalidad, por ejemplo, y es posible decir que antes de la Ley 975 del 2005 no existía un respaldo sólido que pudiera servir de base para concretar y avanzar en los distintos procesos de reparación con el debido reconocimiento que exige un proyecto de esta magnitud; cabe aclarar que esta ley, como las distintas cartas legales que respaldan estos ejercicios, surgieron a partir de un ambiente de lucha social y de exigencia de derechos llevada a cabo de forma colectiva por los distintos gremios y organizaciones de víctimas, quienes, tras ver las atrocidades de la guerra y esperar una ayuda estatal que nunca se dio, salieron a luchar por sus derechos y a pedir la garantía de los mismos, más que por la retribución; su principal propósito fue visibilizar y tener un reconocimiento como víctimas, lo cual sería vital para lograr un avance en los procesos de reparación. (Comité de Impulso para la Reparación Colectiva del Municipio El Castillo, 2018).

Como se mencionó con anterioridad, la Ley 975 del 2005, también conocida como la Ley de Justicia y Paz, fue el primer respaldo legal y hasta ese momento es la única que, de cierta forma, dio aval, hizo un reconocimiento y permitió la visibilización de las organizaciones de víctimas, dando así paso al inicio de una participación por parte de estos actores de la problemática. Pero, ¿de qué manera se daba esta participación y reconocimiento?, los vacíos de esta, como muchas otras leyes y documentos legales en cuanto a las víctimas, son abismales debido a que: 
el lugar asignado a la víctima en el proceso de justicia y paz continúa siendo un lugar secundario al otorgado a los victimarios, puesto que la participación de estas a lo largo del proceso que establece la ley para la investigación y el juzgamiento de los crímenes cometidos por los perpetradores es marginal dentro del andamiaje jurídico que ha sido establecido en la ley misma. (Delgado, 2011. p. 93).

Es decir, que el papel de las víctimas no se reconoce dentro de la participación, simplemente se les da un "atributo" de sujetos de derechos y hasta allí va ese "reconocimiento". Posteriormente, del mismo modo, la Ley 1448 del 2011 reforzó esta idea y le sumo la característica de "reparación Integral” con la cual se buscaba ya no únicamente retribuir monetariamente a las víctimas, sino que, por el contrario, aporta a la idea de participación política y una integralidad en cuanto a educación, salud, desarrollo social, economía y otros aspectos, fomentando una mayor participación y teniendo en cuenta a estos sujetos dentro de los procesos de reparación; sin embargo, estos ejercicios, en el orden regional, se han visto contaminados por estrategias políticas tradicionales que condicionan su implementación.

El caso de las víctimas no se aísla a esta lógica de corrupción, pues las barreras que se presentan en la participación y el ingreso a una "vida política” se tornan en una imposibilidad en el contexto de la representación o participación, y es por consecuencia del miedo y desconfianza frente a las instituciones que, de alguna manera,:

en numerosos casos pueden acabar en el homicidio, asesinato, revictimización, secuestro, extorsión o incluso despojo de su propia cultura, ya que de cualquier forma en la que estas personas exigen la garantía de derechos y velen por la seguridad y por el desarrollo de un gremio, un sector que históricamente ha sido atropellado por las dinámicas del conflicto armado colombiano la respuesta a ellos no es más que la buena fe y el asistencialismo o es la estigmatización social como "guerrilleros", "paramilitares" e incluso como aprovechados de las "oportunidades estatales”. (Instituto Popular de Capacitación, 2009, p. 56)

Para entrar un poco más en detalle en la obstaculización en la participación política de las víctimas, es preciso traer a colación las distintas formas en la que se presenta esta discriminación, revictimización y obstaculización a para ingresar a procesos como actores y sujetos políticos. En primer lugar, es importante resaltar uno de los obstáculos más importantes; e la revictimización 
de los sujetos, pues para nadie es un secreto que en Colombia a las personas con mayor vulnerabilidad se les sigue vulnerando de una u otra forma, lo cual es ilógico, ya que un sujeto en calidad de víctima debería poder recibir la mejor atención, amabilidad y cuidado para mejorar sus condiciones tanto físicas, mentales y afectivas, como económicas y psicosociales, y aún más, cuando el Estado ha sido partícipe de su victimización, pero no es así, los procesos en Colombia ponen "patas arriba” la lógica de las cosas, desde la llegada de una persona a un centro de atención, a la fiscalía, a una estación de policía, a un hospital,, el proceso a seguir se convierte en uno lleno de tropiezos y barreras para realizar cualquier cosa; por su parte, las víctimas que han sufrido de forma directa $\mathrm{o}$ indirecta las injusticias del conflicto armado llegan a un ambiente que pareciera en pro de solucionar, o por lo menos, de mejorar su situación, pero se encuentran con una realidad muy diferente: desde la realización de un RUV (Registro Único de Víctimas) hasta la estipulación de una denuncia se convierte en un tormento para estos sujetos, ya que lo único que logran las personas que los atienden es revivir en carne propia y de la manera más fría y cruda posible los hechos ocurridos, por lo tanto, se sigue estando en un entorno de violencia y no únicamente por la discriminación, sino también porque en todo el proceso se convive con personas ya vulneradas.

\section{Barreras y tensiones de la participación política de las víctimas en los procesos de reparación colectiva en El Dorado y El Castillo}

Durante el proceso de reparación colectiva que se puso en marcha en el municipio de El Dorado a partir del 2015, a lo largo del camino se han ido presentando una serie de barreras que han limitado de una u otra manera el alcance de las actividades planeadas por ejecutar y la participación de los miembros de la comunidad en los distintos escenarios del plan de acción y en los procesos de reparación. Una de las principales limitaciones que se encuentra la población civil es la falta de espacios en la agenda pública, en los cuales se impulse la creación y fortalecimiento de una cultura política que reconozca la importancia de la participación ciudadana, para propiciar dinámicas organizativas de la comunidad en torno a su realidad y sus necesidades.

Se evidencia la baja de organización política en la comunidad, por falta de escenarios participativos que propicien empoderamiento en relación con los 
hechos ocurridos que generaron victimización en gran parte de la comunidad de El Dorado. Esto, a diferencia de otras comunidades que se han organizado a partir del hecho victimizante como ejercicio político, como es el caso de los municipios de El Castillo - Meta y Medellín del Ariari. Lo anterior se explica en la aún presente cultura del miedo y en la implementación del olvido como una forma de afrontamiento que le permite a la comunidad seguir con sus vidas. El olvido se reconoce como una forma de memoria, convirtiéndose en el puente entre el pasado violento que vivió la comunidad y un progreso de tipo económico, que pretende beneficiar más a un grupo de personas, quienes hacen uso de estos procesos sociales para impulsar sus proyectos productivos y económicos.

Así, se dejan en un segundo plano los procesos de recuperación de memoria colectiva, ya que los habitantes del municipio consideran primordial y de mayor urgencia lograr avances de infraestructura que beneficien a la comunidad en general y además algunos otros cuidan sus intereses personales pretendiendo cumplir propósitos propios o que beneficien a un grupo determinado. De esta manera, se deslegitima el valor y la importancia en reconstruir memoria frente a las situaciones y hechos vividos en el territorio, lo cual según Félix Vásquez (2001):

permite que emerja una versión compartida de los acontecimientos por parte de los actores que los vivieron y pueden vivir; no se trata solo de un asunto del pasado. Es decir, que dicha versión involucra diversas perspectivas de significado que le otorgan un sentido de autenticidad, aunque no siempre coincida con la cronología histórica de los hechos que en ocasiones oculta la construcción compartida de la experiencia. La memoria colectiva es, así, una condición exclusiva y estrechamente involucrada con el vínculo social. Por esto, la importancia del estudio de la memoria y de olvidos sociales reside en su carácter de procesos que contribuyen definiendo y articulando el orden social. Vivir en sociedad, señala el autor, implica hacer memoria y hacer olvido. (p. 22).

Los actos de olvido y de no participación dejan entrever que en el municipio aún no se habla abiertamente de lo que pasó ni de los actores reales que causaron esos daños, adicionalmente a ello la perpetuación de legados gamonales y políticos conservadores de la zona hacen que la corrupción sea un fenómeno que excluye a las víctimas como actores válidos en los procesos de reparación. Estas dinámicas son validadas por las entidades estatales y sus funcionarios, quienes en sus planes de gobierno no planean acciones, programas, políticas o estrategias que tengan en cuenta acciones por medio 
de las cuales se logre reconstruir y recuperar la memoria colectiva de la población, sobre todo en territorios que han sido marcados por el conflicto armado interno, que han tenido un fuerte impacto por los hechos ocasionados por los distintos actores armados que tuvieron presencia. Aunque, se han ejecutado planes de reparación colectiva en el municipio, sus gobernantes y, en algunos casos, los principales representantes de la comunidad emplean estos programas para impulsar y promover proyectos de índole económico que nada tienen que ver con los procesos de reparación o de participación política, pero que son plataformas de oportunidad para captar recursos de cooperación internacional y nacionales encaminados a ello.

En comunidades como esta, que han sido golpeadas en gran medida por el conflicto armado, es necesario propiciar espacios participativos en los cuales la población pueda incidir directamente en las decisiones y creación de programas, en este caso, relacionado con la reparación colectiva y los procesos de recuperación de la memoria, de los hechos victimizantes y los daños e impactos que estos causaron y que verdaderamente tenga un efecto positivo y busquen resignificar lo ocurrido, brindándoles a las víctimas la oportunidad de dar nuevos significados y de recuperar la verdad y asegurar la no repetición.

A pesar de que, para efectos de los planes de reparación colectiva que se adelantaron en el municipio, fue necesario realizar un diagnóstico por medio del cual se lograran identificar los daños que fueron perpetrados y qué actores armados los ejecutaron, este en verdad no da cuenta de algunos de los daños que en sus relatos algunos de los miembros de la comunidad dan exponen, lo cual no posibilita llevar a cabo estos planes de acción y que tengan un verdadero impacto positivo en la comunidad y, sobre todo, en las víctimas, ya que los procesos de acompañamiento, que son planeados, se limitaron únicamente para aquellos daños que lograron ser documentados en este diagnóstico. De esta manera, los procesos de acompañamiento psicosocial tienen un papel central en las acciones enmarcadas en la reparación colectiva. La autora Liz Arévalo comenta al respecto:

En este marco, consideramos que el acompañamiento psicosocial tiene como objetivo construir un proceso reflexivo entre la población víctima, su red social y los acompañantes, que contribuya a la superación de los efectos sociales y emocionales de la violencia a través de la resignificación de la identidad y del reconocimiento de recursos personales y sociales, en el marco de la categoría de sujeto de derechos. (Arévalo, 2010, p. 3). 
Entonces, desde lo narrado por los miembros del Comité de Impulso (figura que reposa en la estrategia de reparación colectiva Entrelazando y que tiene como objetivo conformar un grupo que surge de la comunidad para fortalecer procesos de verdad, justicia y memoria) fue posible visibilizar que estos procesos fueron débiles y asistencialistas, ya que las víctimas no tuvieron la oportunidad de superar los daños emocionales resultantes de las épocas de violencia en su territorio y, por el contrario, desde posturas personales y según lo aconsejado por los profesionales encargados se decidió hacer uso de formas de negación como el olvido y el silencio, y suponer que ya todo había pasado y era mejor dejarlo pasar sin volver a construir y resignificarlo. Esto, ha causado en los habitantes de El Dorado actitudes de una falsa superación frente a lo ocurrido, al justificarse que el desarrollo económico ha sido su principal modo de superación y resiliencia, pensamiento que ha sido apoyado por los distintos gobernantes regionales, quienes también han buscado impulsar proyectos económicos con el argumento de que tendrán un efecto en la reparación de la comunidad. Se deduce que el Estado les ha puesto precio a las vidas de las personas que han desaparecido y que han sido asesinadas en estas dinámicas de poder y de conflicto y se ha sobrepuesto y sobrevalorado lo económico frente a la memoria.

De esta manera, retomando lo planteado por el Centro Nacional de Memoria Histórica (2013), para lograr que los procesos de reparación posibiliten la participación y la práctica de la democracia, es necesario permitir que sean escuchadas las voces individuales y colectivas de las víctimas, que han sido invisibilizadas, lo que permitirá su reconocimiento social en la esfera pública. Es un deber posibilitar la participación de todas las personas que estén vinculadas al proceso, desde el reconocimiento del otro como un sujeto de derechos. Entonces, impedir la creación de espacios de participación política afecta directamente los procesos de recuperación de la memoria y, por lo tanto, el reconocimiento de un antes, un durante y un después del conflicto. Pero también, la afirmación de que hubo un antes, un durante y un después del conflicto armado, pues, desde las narrativas de los involucrados, se pueden identificar las acciones y recursos existentes en medio del dolor, que reconozca a las víctimas como agentes políticos y de derecho, con una gran capacidad de resistencia y transformación.

El caso particular del proceso de reparación colectiva en el municipio de El Castillo tiene sus peculiaridades, en cuestión de esto; lo primero por reconocer es la lucha y resistencia social de la comunidad de este municipio, pues existen alrededor de 18 organizaciones, asociaciones, comités y colectivos que están 
en pie de lucha por las distintas problemáticas del territorio, ya sea en el ámbito ecológico, territorial y protección de agua, pero también dentro de una propuesta política de exigencia de derechos, de memoria histórica y colectiva y de lucha social frente a un sistema retrógrada y cosificador del dolor de una comunidad golpeada por el conflicto en gran magnitud. Debido a esto, el reconocimiento del municipio en su totalidad fue a través de una exigencia a la unidad para las víctimas por el reconocimiento de las distintas dinámicas del conflicto que dejaron daños no solamente en el ámbito infraestructural, ya que en términos de tejido social, vivencia en comunidad, características psicosociales, desarrollo rural y agropecuario, se ha visto afectado el territorio.

Es importante reconocer, entonces, que a pesar de que desde el 2014, cuando se reconoció la cabecera municipal como sujeto de reparación colectiva, y posteriormente en el 2016, cuando se reconoce todo el municipio bajo este estatus, el avance en la ruta de reparación colectiva ha sido mínimo, las barreras y trabas desde la institución han sido la realidad social de este municipio en materia de exigencia y reparación, y un panorama preocupante dentro del contexto sociopolítico del país en este momento se avista para sus habitantes, pues las distintas barreras que la institución ha puesto sobre la mesa evidencian los siguientes puntos:

a) En relación con la renovación de contratos y "permisos" para el desplazamiento de los profesionales que acompañan el proceso en el territorio, lo cual ha estancado y parado totalmente el proceso, desconociendo y reincidiendo en la dignidad de las víctimas quienes en total disposición en la realización de los procesos son abofeteados por las lógicas de buró con la que operan instituciones estatales.

b) En términos de la ruta de reparación como tal, un proceso que debe durar seis meses según lo presupuesto por la institución, es un proceso que a la fecha de hoy lleva dos años y medio y está parado desde inicio del 2018, lo cual crea una lógica de desconfianza institucional y sobre todo de desconocimiento del sentir y las necesidades del territorio, que clama por un proceso real, digno y serio de reparación, porque pareciera un juego de cartas en el cual simplemente se revictimiza y se cosifica el sentir de las víctimas, que siendo líderes comunitarios y sociales, participantes de diversas organizaciones sociales, siguen siendo amedrentados, amenazados y perseguidos en un contexto político que atenta contra los derechos y la paz con el gobierno de turno. 
c) La inescrupulosa desatención y olvido de la institución frente a los procesos sociales del territorio, el utilitarismo en el que se ha convertido el proceso con las comunidades, simplemente sacando información y sin retribución alguna en un proceso que cuyo deber ser es por y para las víctimas; de esta forma se desconoce la participación política de las víctimas y se vuelven acciones de una agenda política que realmente NO reparan, NO reconstruyen y siguen reproduciendo lógicas sistemáticas de marginación y desconocimiento de la lucha política y social de las comunidades. (Comité de Impulso para la Reparación Colectiva del Municipio El Castillo, 2018).

Los avances en términos de reparación colectiva son de difícil visualización especialmente en un proceso que ha sido captado por la rigidez y frialdad de una institución estatal como lo es la Unidad para la Atención y Reparación Integral a las Víctimas. De esta forma podríamos decir, que quienes han realizado reparación y reconstrucción (término que la comunidad resalta dentro de este proceso), han sido la misma comunidad y las organizaciones en acompañamiento de otras instituciones no gubernamentales que han realizado acciones reparadoras y sobre todo de reconstrucción en términos de memoria individual, memoria colectiva, memoria histórica, de características psicosociales, de tejido social y vivencia en comunidad.

Como es posible notar, las condiciones y características de los dos casos de reparación colectiva son bastante alejadas la una de la otra, en principio, por el entendimiento de un enfoque diferencial sobre las realidades de cada territorio que han sido muy distantes, pero también por las influencias, relaciones de poder y lógicas corruptas que existen detrás de estos procesos de reparación. en el caso de El Dorado, encontramos una corriente política de derecha, cobijada bajo el control paramilitar en el territorio y que hoy día en los procesos aún se ve, teniendo al lado de la víctima el mismo victimario que juega con la realidad, o solamente cuenta su realidad, con la consecuente burocratización del proceso, con acciones "reparadoras", únicamente con beneficios económicos de por medio, lo que imposibilita y extingue la organización social y la acción popular por medio de lógicas de dominación e imposición de terror que aún se vive en la zona por la presión social y política que estos grupos ejercen.

Por el otro lado, tenemos a media hora de distancia el municipio de El Castillo, una comunidad con una corriente política históricamente de izquierda, cuna y criadero de organizaciones sociales, promotor y protector de derechos humanos, un territorio donde se respira y se escucha el grito de resistencia y el pie de lucha frente a las dinámicas vulneradoras; sin embargo, vemos 
esa marginación en los procesos de reparación, ya que pareciera que hay una constante discriminación y exclusión del pensamiento político de izquierda que hoy día en un conflicto que se ha "finalizado" a través de lo legal con el acuerdo, sigue teniendo fuerza y poder político frente a las comunidades víctimas, resistentes y líderes, lógicas que han imposibilitado el avance y realización de una ruta de reparación colectiva y real, convirtiéndolo en un proceso de agenda política que se ha estancado tras la cosificación del daño y de las víctimas del territorio.

\section{Conclusiones}

Se puede afirmar que el caso de El Dorado (departamento del Meta) se ha sostenido hoy en un cerrado silencio, en donde se han excluido recuerdos colectivos y quizá se ha reducido el potencial de la reparación real que se puede provocar desde lo vivido, en palabras de Nieto (2006. p.7) que aportarían a procesos en donde el descubrimiento de la novedad, de juzgar el presente bajo la luz del pasado, procedimiento que trae indudables y comunes beneficios. Recuerdos colectivos que contribuirían a generar nuevos consensos y puntos de reconciliación o visibilizar asuntos no resueltos para intervenirlos y transformarlos. De acuerdo con Beristain

hay olvidos que no se explican por el paso del tiempo, sino que están motivados emocionalmente. Es decir, hay algunas experiencias que se olvidan porque son de contenido amenazador y evocador de ansiedad, vergüenza o ira, por lo que son entonces reprimidas emocionalmente. En este caso las huellas no son borradas, sino que se vuelven inaccesibles a la conciencia. (2013, p. 67)

El caso de El Dorado se presenta como uno en donde el olvido ha primado, por el miedo, por la habituación a los poderes territoriales hegemónicos y por una subalternizada participación de los sujetos frente a las imposiciones de las políticas estatales, que en muchas ocasiones buscan más la cobertura que la transformación estructural de esas condiciones que perpetúan las formas de violencia; al igual que el olvido, la resistencia política, comprendida como "una forma de confrontación con un poder omnímodo" (Silva, 2014, p. 34) no se ha dado como forma de lucha en este contexto; la resistencia ha tenido su propio devenir en el silencio, opacando las posibilidades de luchas sociales entrampadas en pugnas de poderes locales y restando posibilidades a "la 
multiplicidad de grupos, de células que, desde sus lugares y sin crear unidades y estructuras centralizadas, atacan a los poderes y a sus órganos de represión” (Bensayag, 2000, p. 217) y que podrían generar procesos de resistencia aún desde el silencio.

Es posible afirmar que el caso de El Castillo es un reflejo del juego de poderes y la burocratización de los procesos que realizan instituciones estatales, ya que, a pesar de ser un territorio con sed de reparación y reconstrucción de dinámicas sociales transgredidas por los horrores del conflicto, siguen siendo olvidados y dejados de lado tras el reconocimiento como sujeto de reparación colectiva.

Tenemos, entonces, una prueba palpable y visible de la constante marginación y la dirección a través de las luchas y confrontaciones políticas que existen en estos procesos, pero también tenemos la resistencia y lucha de una comunidad víctima, que ha vuelto a pararse y está diciendo hoy día "somos semilla de una nueva historia”, quienes independientemente han realizado y siguen adelantando acciones reparadoras, de reconstrucción de memoria histórica, de reconocimiento, de reivindicación y restablecimiento de derechos por medio de los distintos procesos sociales que realizan en su quehacer, siendo ejemplo de resistencia dentro del contexto político actual del país.

A manera de conclusión, se puede asegurar que el olvido no se puede estudiar por fuera de los asuntos de memoria, que el olvido está colmado de memoria, estos asuntos se componen principalmente por dos elementos, uno histórico, y el segundo como un ejercicio consciente individual que atraviesa el ámbito colectivo. Por tal razón, en él se presentan entramados profundos de la violencia y, en caso del conflicto en Colombia, hay que desentramarlos para comprender las lógicas con las que aún opera la violencia en algunos territorios en donde las estructuras armadas al margen de la ley han captado las voces de las víctimas. Cabe resaltar que la participación de las víctimas se "reconoce" únicamente desde la Ley 1448 del 2011 como un derecho, planteamiento que en la realidad se ve truncado y hasta imposibilitado por las mismas instancias estatales, por medio de una institucionalización de los procesos en un escenario de estigmatización y discriminación.

En territorios como El Dorado es fundamental comprender que el silencio y el olvido han tenido un lugar en las estrategias para afrontar los hechos victimizantes, que el olvido ha escondido y guardado el dolor que aún no logra hablarse, narrarse y politizarse. En este sentido, es esencial visibilizar 
las complejidades que aún se presentan en los territorios en los cuales aún no se habla abiertamente de lo ocurrido y de los actores implicados en los procesos de violencia, porque no existen garantías reales para las víctimas en escenarios territoriales captados por estructuras político - administrativas herederas del gamonalismo y la violencia política, aún presente, pero con otras formas de operar.

En estos escenarios de silencio y olvido se dificultan los procesos de memoria en tanto las voces de las víctimas y los procesos de visibilización y participación real de estas en procesos de verdad, justicia y reparación enfrentan muchas barreras entre las cuales se pueden enunciar la presencia de actores victimarios en el espacio político administrativo que legalmente se establecen como mecanismos de participación, el direccionamiento de grupos de víctimas como el comité de impulso, que no logran tener una verdadera autonomía por fuera de las reglas y espacios que la Unidad de Víctimas les proporcionan, y la mirada instrumentalista de las figuras que contribuyen a la reparación como la de sujetos de reparación, la cual se ve reducida a ser una plataforma política para la financiación de proyectos direccionados por la lógica estatal.

En territorios como El Castillo, es necesario seguir apoyando y acompañando la lucha social de la comunidad frente al sistema cosificador, por medio de acciones que muestren la realidad del territorio, que permitan comprender los impactos y dinámicas del conflicto armado en el territorio, de esta forma, es de resaltar y aplaudir el trabajo de la comunidad del castillo en materia de memoria colectiva, memoria histórica, de recuperación de relatos, en resignificación y en procesos autónomos e independientes de reparación y recuperación, por su valor de seguir en la lucha en un contexto sociopolítico que oprime y silencia a los que resisten, son una prueba viva de la lucha social campesina, de los saberes en acción, de nuestro derecho a protestar, exigir y sobre todo, a estar inconformes con el sistema y la clases social política.

Para finalizar, es necesario hacer hincapié en el juego de poderes políticos y el desconocimiento a la realidad social de las comunidades víctimas que persisten y laten fehacientemente en los procesos llevados a cabo por instituciones que cosifican y utilizan el dolor, el sentir, la memoria y la dignidad de las víctimas del conflicto armado interno colombiano, lógicas que en estos dos casos que, siendo muy diferentes y llenos de particularidades, son comunes. 


\section{Referencias}

Agencia Presidencial para la Acción Social y la Cooperación Internacional. (2011). Ley de víctimas y restitución de tierras. Bogotá: Presidencia de la República de Colombia.

Arévalo, L. (2010). Atención y reparación psicosocial en contextos de violencia sociopolítica: una mirada reflexiva. Planeta, Bogotá.

Bello Albarracín, M. (2014). Aportes teóricos y metodológicos para la valoración de los daños causados por la violencia. Bogotá: Centro Nacional de Memoria Histórica.

Bensayag, M. y Sztulwark, D. (2000). Política y situación. De la potencia al contrapoder. Buenos Aires: De Mano en Mano.

Centro Internacional de Justicia Transicional. (2015). Estudio sobre la implementación del Programa de Reparación Individual en Colombia. Recuperado el 05/12/2018 del Centro Internacional de Justicia Transicional: https://www.ictj. org/sites/default/ files/ICTJ-COL-Estudio-reparacion-individual-2015.pdf

Centro Nacional de Memoria Histórica. (2011). Ley de Víctimas y Restitución de Tierras. Recuperado el 03/03/2018, de https://www.centrodememoriahistorica.gov.co/micrositios/ caminosParaLaMemoria/descargables/ley1448.pdf

Centro Nacional de Memoria Histórica.(2013). Tejiendo Memoria. Orientaciones pedagógicas. Proceso pedagógico del informe San Carlos. Memorias del éxodo en la guerra. Colombia.

Centro Nacional de Memoria Histórica. (2014). Guerrilla y población civil. En C. d. Histórica, Guerrilla y población Civil (págs. 143-150). Bogotá.

Centro Nacional de Memória Histórica (2015). Pueblos arrasados, memorias del desplazamiento forzado en El Castillo (Meta). Bogotá.

CODHES. (2017). Ajustes urgentes a la ruta étnica de reparación colectiva. En CODHES, Reparación colectiva y paz territorial: una propuesta para ajustar la actual ruta administrativa en el marco del acuerdo entre el Gobierno y las Farc -EP (págs. 1721). Bogotá: CODHES.

Comisión Histórica del Conflicto Armado. (2015). Contribución al entendimiento del conflicto armado en Colombia. Recuperado el 05/12/2018 de: http://www.humanas. unal.edu.co/observapazyconflicto/files/5714/6911/9376/Version_final_informes_ CHCV.pdf

Cuervo, I. (2012). Barreras e incentivos para que las mujeres víctimas de violencia sexual en el contexto del conflicto armado participen en los procesos de exigibilidad de verdad, justicia y reparación en Colombia (tesis de Maestría).Pontificia Universidad Javeriana. Bogotá.

Delgado, M. (2011). Las víctimas como sujetos políticos en el proceso de justicia y paz en Colombia: discursos imperantes y disruptivos en torno a la reconciliación, la verdad, la justicia y la reparación. Tesis doctoral. FLACSO México. México 
Díaz, L. (2009). El rostro de los invisibles. Víctimas y su derecho a la verdad, justicia, reparación y no repetición. En: Bondia, D.; Muñoz, M. Víctimas invisibles, conflicto armado y resistencia civil en Colombia (Pp. 37-72). Barcelona: Huygens Editorial

Echavarría Rentería, Y., \& Hinestroza Cuesta, L. (2016). Análisis del marco jurídico para la reparación colectiva a grupos étnicos en Colombia: caso comunidades negras del Chocó. Estudios de Derecho. 73 (161). Pp. 125-154.

Garay, L. J., Vargas, F., Salgado, C. (2016). Daño, verdad, reparación colectiva y construcción de paz en Colombia. Lecturas de reparación colectiva. Volumen 1. Bogotá: CODHES -USAID.

Halbwachs, M. (1968). La memoria colectiva. París: Presses Universitaires de France.

Halbwachs, M. (1991). Fragmentos de la memoria colectiva. En: Revista de Cultura y Psicología 1 (1). UNAM. México.

Instituto Popular de Capacitación.(2009). El péndulo de la violencia: rupturas y continuidades en el conflicto. Medellín: Instituto Popular de Capacitación.

Molano, A. (1989). Aproximación al proceso de colonización de la región del AriariGüejar-Guayabero. Recuperado el 05/12/18 de: http://www.bdigital.unal.edu. co/1435/7/05CAPI04.pdf

Nieto, J. El deber de la memoria, la imposibilidad del olvido. Alcances ético-políticos. Reflexión Política, vol. 8, núm. 15, junio de 2006, pp. 80-92.

Observatorio del Programa Presidencial de Derechos Humanos y DIH. (2007). Diagnóstico departamental del Meta. Consejería Presidencial para los Derechos Humanos. Recuperado el 02/09/2018 de: http://historico.derechoshumanos.gov. co/Observatorio/DiagnosticoEstadisticoDepto/dd/2003-2007/meta.pdf

PNUD. (2010). Meta: análisis de la conflictividad. Recuperado el 02/09/2018 de: http://www.undp.org/content/dam/undp/documents/projects/COL/00058220_ Analisis\%20conflictividad\%20Meta\%20PDF.pdf

Proyecto Colombia Nunca Más. (2000). Colombia Nunca Más, Crímenes de lesa Humanidad. En ONG, Colombia Nunca Más. Bogota: Equipo Nizkor y Derechos Human Rights.

Reátegui, F., Briceño-Donn, M., Uprimny, M. (2009). Recordar en conflicto: iniciativas no oficiales de memoria en Colombia. Recuperado el XXXXX de: https://www.ictj.org/ sites/default/files/ICTJ-Colombia-Unofficial-memoryinitiatives-July2009-Spanish. pdf

Reunión: Comité de Impulso para la Reparación Colectiva del municipio El Castillo-Meta con grupo de investigación de estudiantes de la Universidad de La Salle a cerca de los avances y dinámicas del proceso de reparación colectiva en el territorio. (mayo 2018).

Unidad para la Atención y Reparación Integral a Víctimas. (2014). Procedimiento de reparación colectiva. Bogotá: Unidad para la Atención y Repración Integral a Víctimas. 
Vargas, J. (2003). Teoría de la acción colectiva, sociedad civil y los nuevos movimientos sociales en las nuevas formas de gobernabilidad en Latinoamérica. En: Espacio abierto 12 (4). Pp. 523-537. Maracaibo, Venezuela.

Vásquez, F. (2001). La memoria como acción social. Relaciones, significados e imaginarios. Paidós. Barcelona.

Zamora, J. A. \& Reyes, M. (Eds.). (2011). Justicia y memoria. Hacia una teoría de la justicia anamnética. Barcelona: Anthropos. 